\title{
Enhanced MJO-like Variability at High SST
}

\section{Citation}

Arnold, Nathan P., Zhiming Kuang, and Eli Tziperman. 2013. “Enhanced MJO-Like Variability at High SST." Journal of Climate 26, no. 3: 988-1001.

\section{Published Version}

doi:10.1175/jcli-d-12-00272.1

\section{Permanent link}

http://nrs.harvard.edu/urn-3:HUL.InstRepos:13041333

\section{Terms of Use}

This article was downloaded from Harvard University's DASH repository, and is made available under the terms and conditions applicable to Other Posted Material, as set forth at http:// nrs.harvard.edu/urn-3:HUL.InstRepos:dash.current.terms-of-use\#LAA

\section{Share Your Story}

The Harvard community has made this article openly available.

Please share how this access benefits you. Submit a story.

\section{Accessibility}




\title{
Enhanced MJO-like Variability at High SST
}

\author{
NATHAN P. ARNOLD \\ Department of Earth and Planetary Sciences, Harvard University, Cambridge, Massachusetts \\ ZHIMING KUANG AND ELI TZIPERMAN \\ Department of Earth and Planetary Sciences, and School of Engineering and Applied Sciences, \\ Harvard University, Cambridge, Massachusetts
}

(Manuscript received 11 May 2012, in final form 30 July 2012)

\begin{abstract}
The authors report a significant increase in Madden-Julian oscillation (MJO)-like variability in a superparameterized version of the NCAR Community Atmosphere Model run with high sea surface temperatures (SSTs). A series of aquaplanet simulations exhibit a tripling of intraseasonal outgoing longwave radiation variance as equatorial SST is increased from $26^{\circ}$ to $35^{\circ} \mathrm{C}$. The simulated intraseasonal variability also transitions from an episodic phenomenon to one with a semiregular period of 25 days. Moist static energy (MSE) budgets of composite MJO events are used to diagnose the physical processes responsible for the relationship with SST. This analysis points to an increasingly positive contribution from vertical advection, associated in part with a steepening of the mean vertical MSE profile in the lower troposphere. The change in MSE profile is a natural consequence of increasing SST while maintaining a moist adiabat with a fixed profile of relative humidity. This work has implications for tropical variability in past warm climates as well as anthropogenic global warming scenarios.
\end{abstract}

\section{Introduction}

Surface temperatures in the tropical belt have varied significantly over geologic time (e.g., Dowsett and Robinson 2009; Pearson et al. 2007) and are projected to increase by $2^{\circ}-3^{\circ} \mathrm{C}$ over the twenty-first century (Meehl et al. 2007). Understanding the climate response to these variations, in particular that of moist convection and accompanying large-scale circulations, is of tremendous practical importance. Considerable work has been done establishing global constraints on the convective response to warming (e.g., Held and Soden 2006) and quantifying changes in extreme events (e.g., Muller et al. 2011). However, with the notable exception of tropical cyclones, less attention has been paid to the response of organized convective variability and in particular the wavelike modes seen in equatorial spectra.

Here we study the dependence of organized tropical convection on mean sea surface temperature (SST) in an aquaplanet general circulation model (GCM) that

Corresponding author address: Nathan Arnold, Harvard University, 24 Oxford St., Cambridge, MA 02138.

E-mail: narnold@fas.harvard.edu generates an intraseasonal disturbance strongly resembling the observed Madden-Julian oscillation (MJO). First identified by Madden and Julian (1971), the MJO may be regarded as a multiscale structure with a broad $(10000 \mathrm{~km})$ envelope of enhanced deep convection coupled to neighboring regions of suppressed convection through a large-scale overturning circulation. The convectively active phase typically originates over the Indian Ocean or west Pacific Ocean and propagates eastward at roughly $5 \mathrm{~m} \mathrm{~s}^{-1}$ before dissipating over the cooler waters of the east Pacific. A convectively uncoupled signal in surface pressure and zonal wind may continue eastward at higher speed. This basic description omits seasonality, meridional propagation, and other details; we refer the reader to Zhang (2005) for a more complete review.

Observational evidence for a dependence of intraseasonal variability (ISV) on SST is limited and is complicated by spatially inhomogeneous patterns of warming and cooling. Changes in the tropical SST distribution can alter the large-scale circulation and result in dynamic forcing of convection, regardless of mean SST. Nevertheless, weak positive trends in ISV are seen in the $\mathrm{Na}$ tional Centers for Environmental Prediction-National 
Center for Atmospheric Research (NCEP-NCAR) reanalysis (Jones and Carvalho 2006) and the Twentieth Century Reanalysis (Oliver and Thompson 2012) over the last four decades, during which time tropical SSTs have increased by roughly $0.5^{\circ} \mathrm{C}$. Similarly, interannual variability in $\mathrm{MJO}$ activity shows a weak correlation with SST over the Indian and west Pacific Oceans (Hendon et al. 1999). It is clear that processes other than local SST dominate MJO variability at the interannual time scale, but this should not be surprising given that interannual SST anomalies in these regions are typically $0.5^{\circ} \mathrm{C}$ or less. It is unclear what effect a more substantial and sustained change in mean SST would have on ISV.

The quest for a complete theoretical description of the MJO is ongoing, despite improved observational constraints (e.g., Kiladis et al. 2005; Benedict and Randall 2007; Grodsky et al. 2009; Kiranmayi and Maloney 2011), guidance from numerical models (e.g., Benedict and Randall 2009; Maloney 2009; Kim et al. 2011), and recent theoretical developments (e.g., Fuchs and Raymond 2002; Raymond and Fuchs 2009; Kuang 2011). There are currently a number of viable approaches, not all mutually exclusive. Some emphasize the role of scale interaction (e.g., Majda and Biello 2004; Majda and Stechmann 2009), while others focus on small-scale physical processes and thermodynamic feedbacks (e.g., Raymond 2001; Sobel et al. 2010). Many of the prevailing ideas are summarized and evaluated by Sobel and Maloney (2012).

The importance of environmental humidity was recognized early on. Entrainment of environmental air into a convecting plume results in evaporative cooling and loss of buoyancy, such that the vigor of deep convective activity is tied directly to the environmental relative humidity; deep convection is suppressed in dry environments and encouraged in moist ones. Blade and Hartmann (1993) proposed a "discharge-recharge" hypothesis in which the time scale of the MJO is set by the buildup (recharge) of column moisture by shallow, nonprecipitating convection, which preconditions the atmosphere for strong deep convection. Deep convection results in moisture discharge and drying of the column and a return to the recharge phase of the oscillation.

We interpret our results within the "moisture mode" paradigm, which has appeared under various guises in previous work (e.g., Sobel et al. 2001; Fuchs and Raymond 2002; Raymond and Fuchs 2009). In this context, the MJO is viewed as an essentially linear instability resulting from the covariation of column moist static energy anomalies with sources or sinks thereof. In other words, a moisture mode instability will occur when the effective gross moist stability (Neelin and Held 1987; Raymond et al. 2009)—including sources and sinks of moist static energy (MSE) due to surface fluxes, radiative heating, and horizontal advection-is negative.

A moisture mode is distinct from the classical spectrum of shallow water waves, whose underlying dynamics may operate in a dry atmosphere and are merely modulated by interaction with moist convection rather than fundamentally dependent on it (Kiladis et al. 2009). The classification of the MJO as a moisture mode is suggested by wavenumber-frequency spectra of MSE, which typically retain an MJO signal but show reduced power around the shallow water wave dispersion curves (e.g., Roundy and Frank 2004; Andersen and Kuang 2012). However, a fundamental distinction between the MJO and other convectively coupled waves is not universally accepted (Roundy 2012). Some also argue that nonlinearities may be important to MJO dynamics (Sobel and Maloney 2012).

Simulation of the MJO in GCMs has been notoriously poor, with few exceptions (Lin et al. 2006), and recent work suggests that an insensitivity of parameterized convection to environmental humidity is a major contributing factor (Thayer-Calder and Randall 2009). Despite this lack of model realism, we note two studies that found a dependence of ISV on SST in comprehensive GCMs: Lee (1999) reported increased ISV after a uniform $2{ }^{\circ} \mathrm{C}$ SST perturbation in a Geophysical Fluid Dynamics Laboratory AGCM, and Caballero and Huber (2010) found an increase in ISV in several configurations of the NCAR Community Atmosphere Model version 3.1 (CAM3.1) over a wide range of SST. These studies did not identify a mechanism for the increased variability.

Here we have elected to use a superparameterized (SP) version of the CAM3.5 run in a zonally symmetric aquaplanet configuration. The decision to use SP-CAM was based on two factors. First, the track record of SPCAM in simulating a realistic MJO is better than most other GCMs to date (Kim et al. 2009). Second, because superparameterization is a fundamentally different method of representing convection, it offers an independent test of the model results noted above, which relied on conventional convection parameterizations.

There is a long history of numerical studies of the MJO that treat the earth as an aquaplanet (e.g., Hayashi and Sumi 1986; Swinbank et al. 1988; Numaguti and Hayashi 1991; Lee et al. 2003; Grabowski 2003; Maloney et al. 2010). This approach has the advantage of simplifying the analysis and highlighting any changes in dynamics. On the other hand, it immediately sacrifices certain features like seasonality and the influence of topography, which may be relevant to some studies (e.g., Wu and Hsu 2009). More subtle aspects of the MJO may also be affected. For example, Lin et al. (2005) note that 
the mean winds in a zonally symmetric basic state may result in biases by altering the phasing of temperature and heating anomalies, thereby reducing the efficiency of eddy available potential energy generation. Similarly, the presence of mean surface westerlies over the Indian Ocean is thought to be important in controlling the phasing of surface fluxes during MJO events (e.g., Maloney et al. 2010), and the easterly surface winds in a zonally symmetric state may affect MJO growth and propagation. Nevertheless, the ability of many numerical models to simulate MJO-like disturbances both with and without zonal asymmetries and topography suggests that the phenomenon may be profitably studied with an idealized setup.

In this study, we present a set of simulations forced with globally uniform increases in SST, in which SPCAM produces a monotonic and significant increase in MJO-like variability, documented in section 3. In section 4, we present a composite MSE budget of the model $\mathrm{MJO}$ and attempt to provide an explanation for the increase in variability. Because of the lack of a general theory for the MJO, this attempt is necessarily incomplete, but we believe it provides a compelling direction for future work. Section 5 contains a general discussion of these findings, and we summarize our conclusions in section 6 .

\section{Model description and experiments}

\section{a. Model description}

In a superparameterized GCM, the conventional boundary layer and convection parameterizations are replaced with a two-dimensional cloud-system-resolving model (CSRM) embedded within each GCM grid cell (Grabowski 2001; Randall et al. 2003). Thus, grid-scale cloud statistics and thermodynamic tendencies are generated through explicit simulation with the exception of the cloud microphysics, which remain parameterized. A brief history of the superparameterization technique is provided by Khairoutdinov et al. (2005). A superparameterized scheme was implemented in the NCAR CAM by Khairoutdinov and Randall (2001). The host GCM for the present study is CAM3.5, using a semi-Lagrangian dynamical core with $2.8^{\circ} \times 2.8^{\circ}$ horizontal resolution, 30 vertical levels, and a time step of $15 \mathrm{~min}$. The CSRM is based on the three-dimensional System for Atmospheric Modeling (SAM), described in detail by Khairoutdinov and Randall (2003). In this study, each CSRM domain is an east-west strip of 32 columns with $4-\mathrm{km}$ horizontal resolution, a 20 -s time step, and a vertical grid matching the lower 28 levels of the GCM. The boundary conditions are periodic, which precludes any movement of cloud systems between GCM grid cells; convective propagation can occur only through its influence on large scales.

The CSRM influences the GCM grid-scale fields through addition of the CSRM domain-averaged moisture and temperature tendencies, while the CSRM is relaxed toward the GCM fields to prevent drift from the large-scale climate. The 2D CSRM domain does not allow realistic transport of both components of horizontal momentum by convection (i.e., "cumulus friction"), so momentum tendencies are not returned to the GCM.

The superparameterization results in a number of improvements over the conventional model, including a realistic diurnal cycle of precipitation and less tendency to "drizzle" (Khairoutdinov et al. 2005). Most significant for this study, SP-CAM simulates much stronger intraseasonal variability (ISV) than the conventional CAM. The stronger ISV in SP-CAM has been attributed to a greater sensitivity of precipitation to the total column moisture; at higher relative humidities, convective entrainment of environmental air results in less evaporative cooling, greater net convective heating, and a stronger large-scale circulation (Thayer-Calder and Randall 2009). If anything, SP-CAM produces a column that is overly moist and generates ISV somewhat stronger than observed. The MJO in SP-CAM has a generally realistic temporal evolution, with preconditioning of the middle troposphere by anomalous meridional convergence of moisture and a rapid moisture discharge following deep convection (Benedict and Randall 2009).

Previous superparameterization studies have shown some sensitivity to the details of the CSRM configuration. For example, use of a 3D CSRM domain and the addition of momentum coupling were shown to reduce a bias in mean precipitation over the west Pacific warm pool (Khairoutdinov et al. 2005). To test the sensitivity of the results presented here, we run a pair of 2-yr simulations with an equatorial SST of $35^{\circ} \mathrm{C}$. In the first, we increase the CSRM resolution from 4 to $1 \mathrm{~km}$ and change the orientation from eastwest to north-south. In the second, we use a 3D domain of $32 \mathrm{~km}$ by $32 \mathrm{~km}$ with 4-km grid spacing (and no momentum coupling). Statistics from the last 21 months of each simulation are compared with the $35^{\circ} \mathrm{C}$ case discussed below. We find no significant differences in either the mean state or intraseasonal variability and conclude that our basic results are relatively insensitive to the CSRM geometry and resolution. Khairoutdinov and Randall (2003) also report some sensitivity to microphysics parameters, but these are not examined here. 

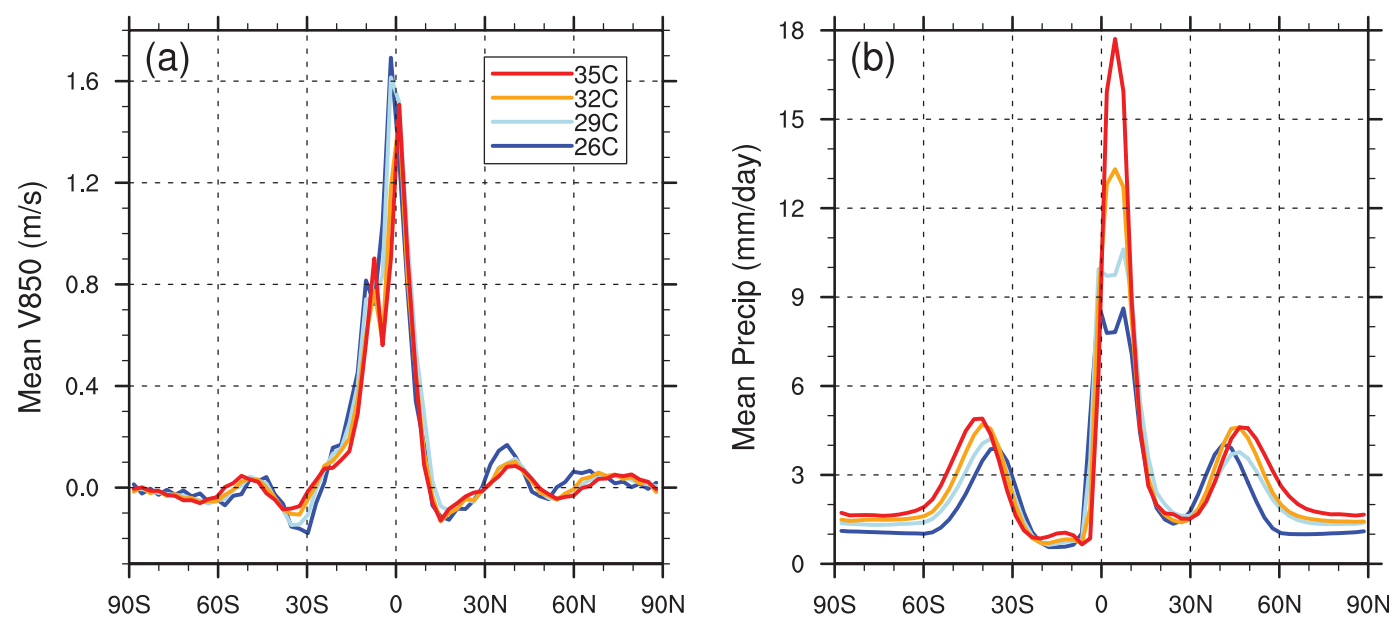

FIG. 1. Time- and zonal-mean (a) 850-hPa meridional wind and (b) precipitation.

\section{b. Experimental setup and mean state}

We use an aquaplanet configuration in which SP-CAM was previously shown to generate MJO-like variability, and the base state $\mathrm{MJO}$ (with $T_{0}=29^{\circ} \mathrm{C}$ ) was thoroughly characterized by Andersen and Kuang (2012). The prescribed sea surface temperatures are given as a function of latitude $\phi$ by

$$
T(\phi)=T_{0}-\Delta T\left(\zeta+\zeta^{2}\right)
$$

where

$$
\zeta= \begin{cases}\sin ^{2}\left(\pi \frac{\phi-5}{110}\right), & 5<\phi \leq 60 \\ \sin ^{2}\left(\pi \frac{\phi-5}{130}\right), & -60 \leq \phi \leq 5 \\ 1, & |\phi|>60\end{cases}
$$

such that the peak SST is offset from the equator to $5^{\circ} \mathrm{N}$ and $\Delta T$ is fixed at $13.5^{\circ} \mathrm{C}$. Insolation is set to a perpetual equinox, though the diurnal cycle is retained.

The prescribed SST pattern results in a mean state reminiscent of boreal summer over the central Pacific, although the lack of zonal asymmetry precludes a Walker circulation. The meridional circulation is dominated by a Southern Hemisphere Hadley cell, with strong low-level convergence and precipitation centered on the SST maximum (Fig. 1). Midlatitude eddy activity is comparable to observations.

To study the dependence of MJO activity on mean SST, we run a set of simulations in which $T_{0}$ is varied from $26^{\circ}$ to $35^{\circ} \mathrm{C}$, in increments of $3^{\circ} \mathrm{C}$, with a fixed meridional gradient. Our focus here is not on the mean state, but we note that the mean lower-tropospheric mass convergence remains roughly constant, as suggested by the zonal-mean $850-\mathrm{hPa}$ meridional velocity (Fig. 1a), while precipitation along the model's "ITCZ" increases significantly (Fig. 1b). Importantly, but not surprisingly, the relative humidity remains roughly constant (not shown).

A uniform surface warming is an obviously imperfect representation of the response to greenhouse gas forcing or the anomalies of past warm climates, which can vary spatially and result in large-scale circulation changes, in turn forcing dynamic changes in convection (Bony et al. 2004). Like the idealized aquaplanet geometry, a uniform warming is meant to capture the first-order thermodynamic response and allow us to identify simple physical principles. Further work will be needed to understand the effects of changing large-scale dynamics and other real-world complications.

\section{Intraseasonal variability increases with SST}

Hovmöller plots of outgoing longwave radiation (OLR) along the equator are shown in Fig. 2 for each simulation. As SST is increased, high clouds become increasingly organized into eastward propagating bands. The organized variability also transitions from an essentially episodic phenomenon to one with a semiregular period of about 25 days, where events tend to circumnavigate the globe two or three times before dissipating, followed by rapid organization of a subsequent event. Hovmöller plots of other variables associated with organized convection (precipitation, column moisture, zonal wind) show a similarly striking dependence on SST.

Wavenumber-frequency power spectra offer quantitative support for these changes. These are calculated as 

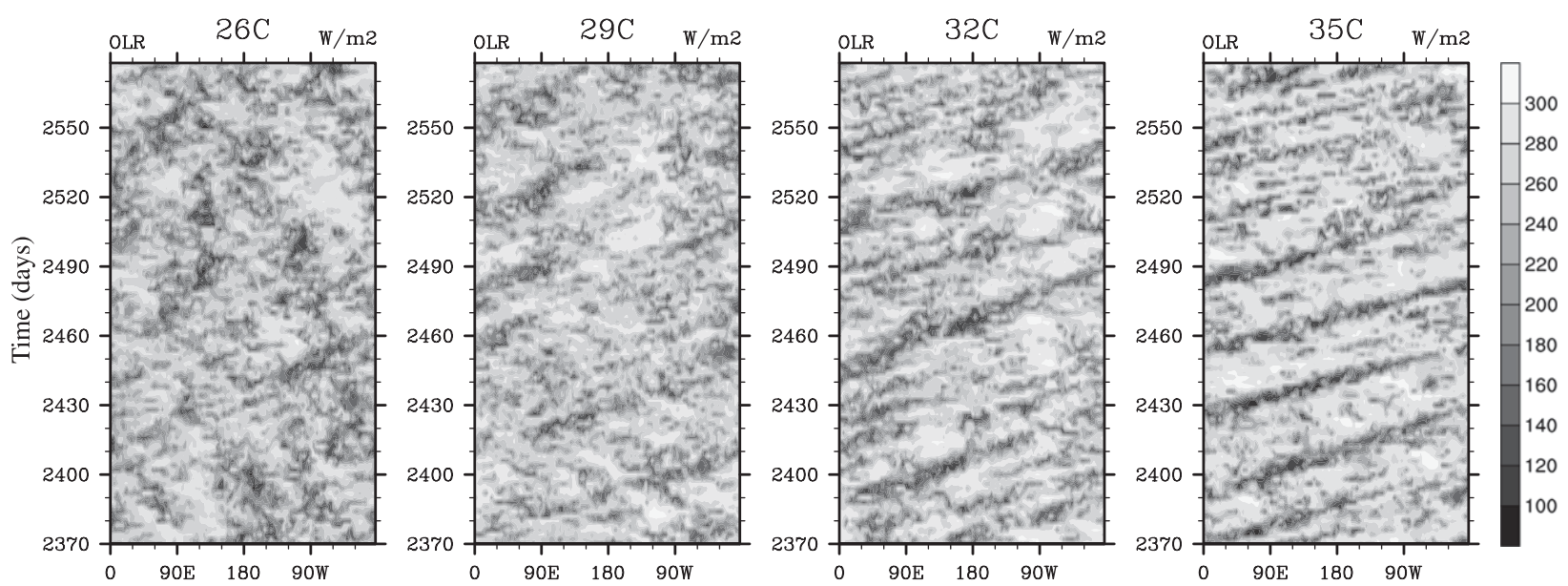

FIG. 2. Hovmöller plots of equatorial OLR from year 6 of each simulation. A significant increase in cloud organization is visible moving from (left) low to (right) high SST.

in Wheeler and Kiladis (1999), using OLR averaged between $5^{\circ} \mathrm{S}$ and $5^{\circ} \mathrm{N}$, with the exception that we do not divide by a smoothed background spectrum and do not take the logarithm of the power. For the $26^{\circ} \mathrm{C} \mathrm{SST}$ case (Fig. 3a), a MJO-like signal is seen around zonal wavenumber two and a period of 40 days. The model also produces enhanced energy around the Kelvin and Rossby wave bands predicted by linear shallow-water theory (e.g., Matsuno 1966) and modified through coupling with moist convection (e.g., Mapes 2000; Kuang 2008), with phase speeds and peak space-time scales generally consistent with observed OLR spectra (Wheeler and Kiladis 1999).

The difference in the $35^{\circ} \mathrm{C}$ case (Fig. 3b) is dramatic. While the total OLR variance remains roughly constant, the intraseasonal variance contained in wavenumbers 1-3 and periods of 20-100 days more than triples, and the ratio of eastward to westward ISV rises from 1.95 to 6.27. There is a somewhat smaller increase in variance along the Kelvin wave band, as well as an increase in phase speed, from roughly $12 \mathrm{~m} \mathrm{~s}^{-1}$ at $26^{\circ} \mathrm{C}$ to $19 \mathrm{~m} \mathrm{~s}^{-1}$ at $35^{\circ} \mathrm{C}$. We also see a steady increase in the MJO frequency, such that in the $35^{\circ} \mathrm{C}$ case (Fig. 3b) the MJO signal is overlapping with the Kelvin wave band, though it is still visible as a distinct peak. The movement of the peak in spectral space is continuous across the four simulations, which reassures us that it corresponds to the same underlying phenomenon. Though the increase in both Kelvin wave and MJO variance is intriguing given their different dynamical bases, for now we focus on the
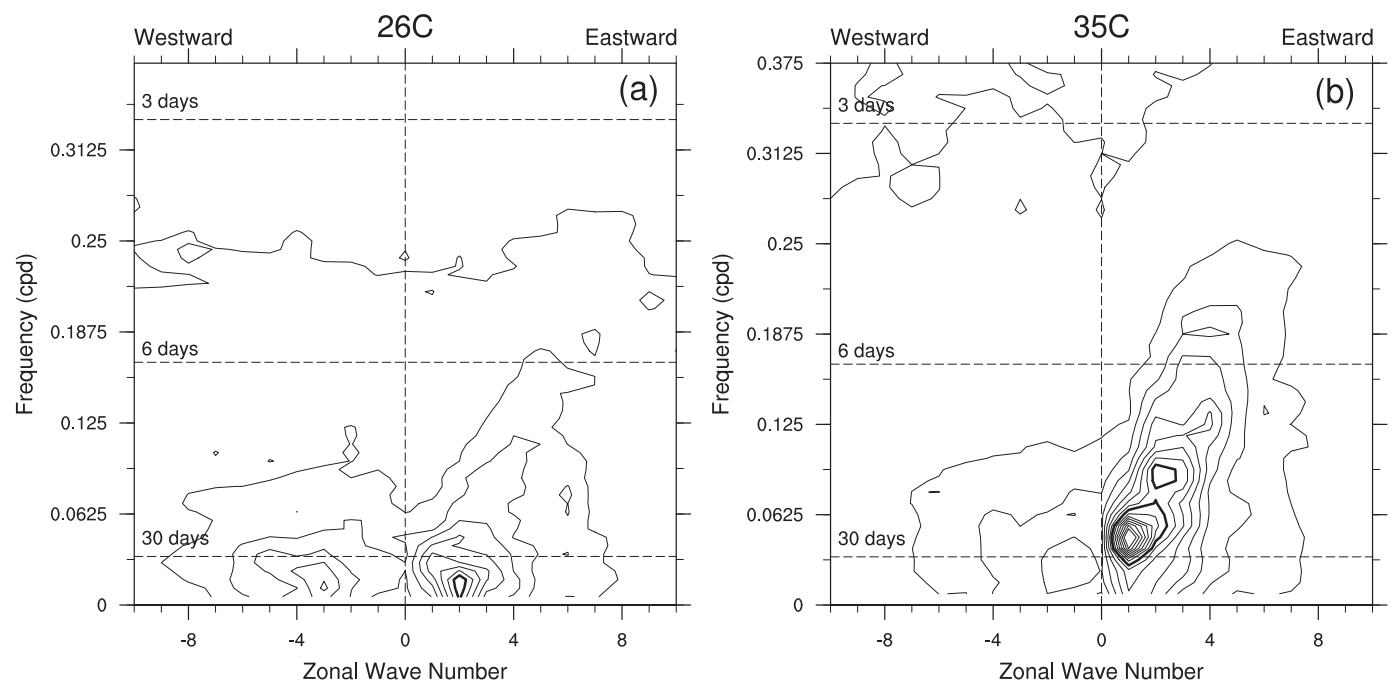

FIG. 3. Wavenumber-frequency power spectra of OLR for the (left) $26^{\circ}$ and (right) $35^{\circ} \mathrm{C}$ simulations. Contour intervals are $1 \mathrm{~W}^{2} \mathrm{~m}^{-4}$; the $9 \mathrm{~W}^{2} \mathrm{~m}^{-4}$ contour is bold in both panels. 

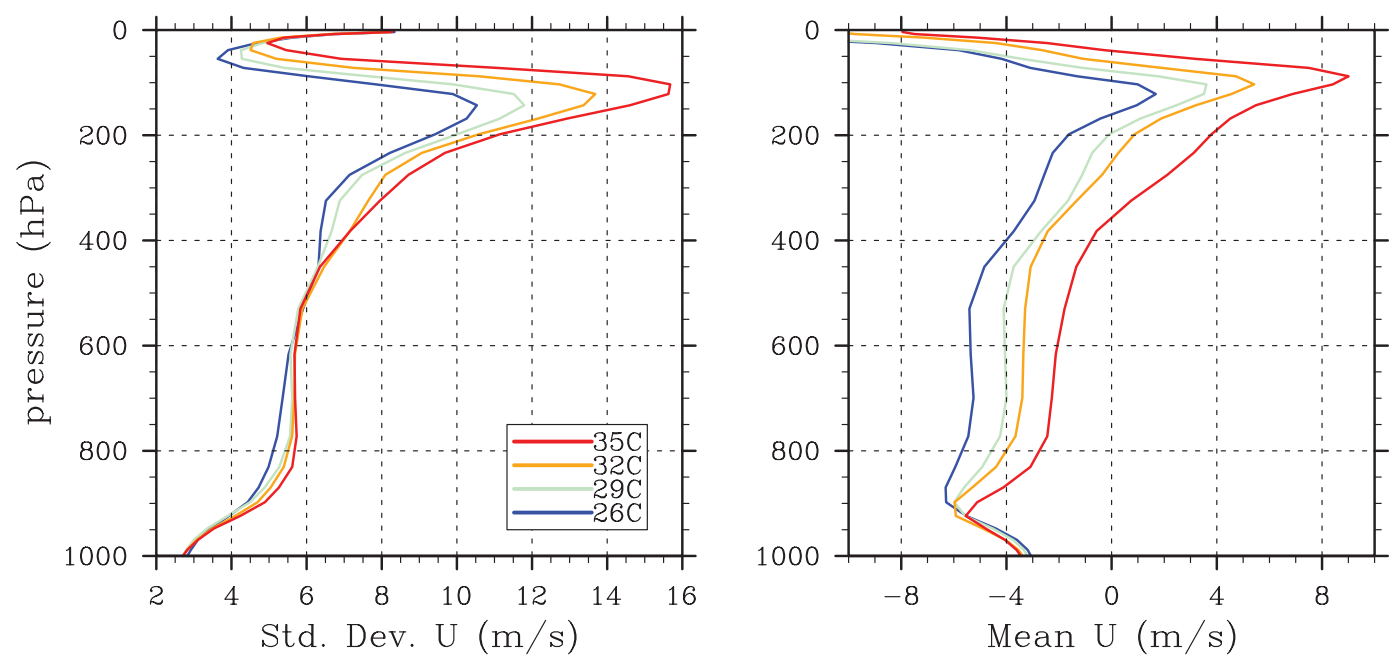

FIG. 4. The daily (left) standard deviation and (right) time- and zonal-mean of equatorial zonal wind between $5^{\circ} \mathrm{S}$ and $5^{\circ} \mathrm{N}$.

MJO-like disturbance, which shows the greatest change in variance.

Increases in intraseasonal variability have led to atmospheric superrotation-westerly equatorial windsin previous studies (Lee 1999; Caballero and Huber 2010; Arnold et al. 2012), and we observe a similar trend toward equatorial westerlies as the SST is increased (Fig. 4). The westerly acceleration is driven by the meridional convergence of zonal momentum in the upper-tropospheric gyres of MJO-like disturbances. Superrotation remains weak $\left(<10 \mathrm{~m} \mathrm{~s}^{-1}\right)$ in these simulations due to the strong easterly torque provided by the perpetual winter Hadley cell, through its advection of low-angular-momentum air across the equator (Kraucunas and Hartmann 2005). Even so, the mean zonal winds increase by roughly $4 \mathrm{~m} \mathrm{~s}^{-1}$ throughout the troposphere across these simulations, and may account for a substantial fraction of the increased propagation speed of the MJO and Kelvin waves. In related SP-CAM simulations with a SST maximum of $35^{\circ} \mathrm{C}$ centered on the equator, we find a westerly mean equatorial wind in excess of $20 \mathrm{~m} \mathrm{~s}^{-1}$ above $200 \mathrm{hPa}$.

\section{Moist static energy budget}

Comprehensive moist static energy (MSE) budgets have been used in several recent modeling (Maloney 2009; Andersen and Kuang 2012) and observational (Kiranmayi and Maloney 2011) studies to shed light on MJO dynamics. While the datasets and compositing techniques differ, these studies suggest certain common features. In each case, anomalous advective tendencies lead to a buildup of MSE to the east of an existing MSE anomaly and, thus, to eastward propagation. The modeling studies (Maloney 2009; Andersen and Kuang 2012) find that this advection is dominated by the horizontal component associated with modulation of synoptic eddies by the anomalous large-scale flow, while in reanalysis products (Kiranmayi and Maloney 2011) the vertical advection plays a larger role. In each case, anomalous radiative heating tends to covary with the MSE, slowing the rate of MSE discharge by convection. The surface fluxes are less consistent-in some cases playing an essential role and in other cases negligible.

The temporal evolution in all of these composites is consistent with the recharge-discharge paradigm of Blade and Hartmann (1993) in which the MJO is described by a buildup of column moisture (MSE), which preconditions the atmosphere for deep convection followed by discharge of MSE during the deep convective phase.

To identify the reason for increasing ISV with SST, we calculate the vertically integrated MSE budgets for composite MJO events, following the methodology of Andersen and Kuang (2012). The vertical integral allows us to avoid dealing explicitly with convective processes, which vertically redistribute, but approximately conserve, MSE. Due to the predominance of high clouds in our region of interest, we use the frozen moist static energy,

$$
h=g Z+c_{p} T+L_{v} q-L_{f} q_{i},
$$

where $q$ is the specific humidity, $q_{i}$ water ice, $Z$ geopotential height, $T$ temperature, $g$ gravity, $c_{p}$ the heat capacity of dry air at constant pressure, and $L_{v}$ and $L_{f}$ are the latent heats of vaporization and fusion, respectively. This form of MSE is conserved under phase changes including ice formation and melting. 

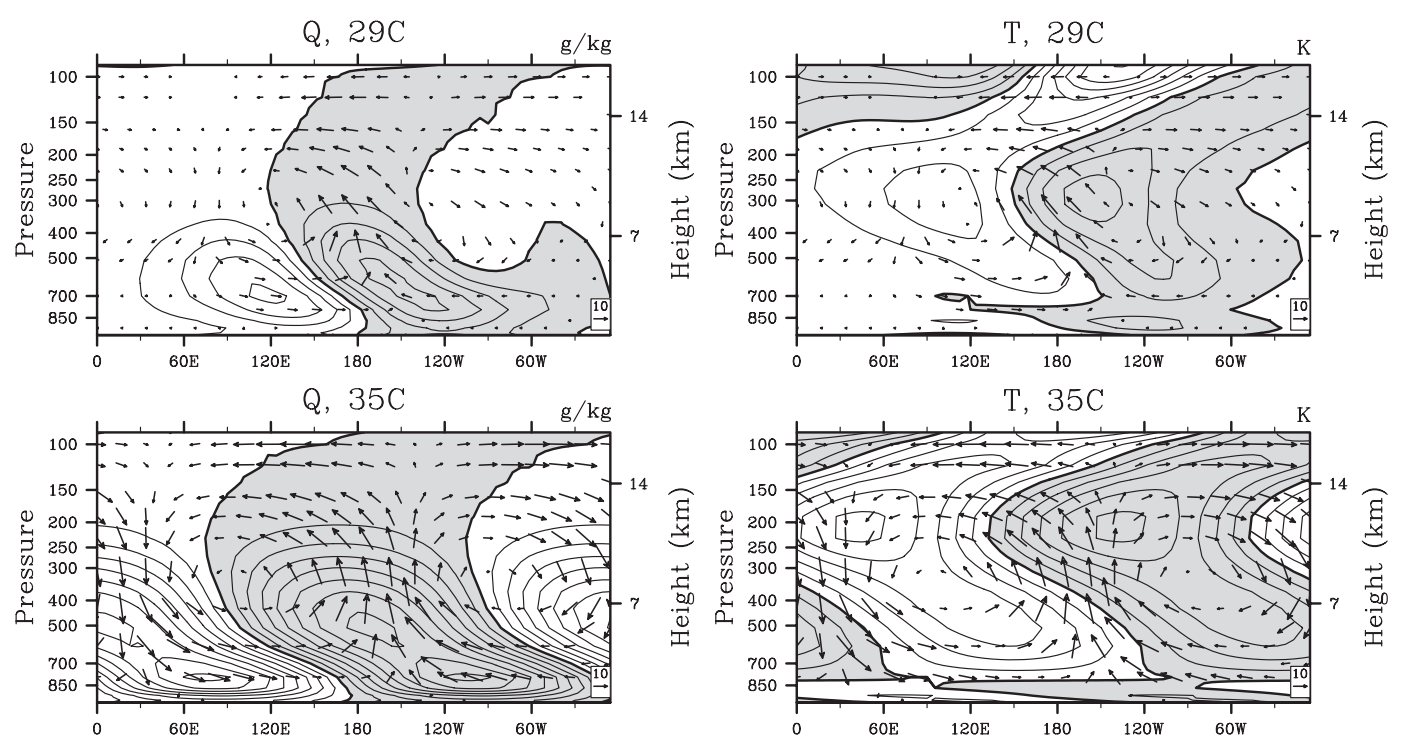

FIG. 5. Equatorial longitude-height profiles of composite (left) specific humidity and (right) temperature for the MJO in the (top) $29^{\circ}$ and (bottom) $35^{\circ} \mathrm{C}$ simulations. Humidity contours are $0.2 \mathrm{~g} \mathrm{~kg}^{-1}$, temperature contours are $0.2 \mathrm{~K}$, and positive values are shaded. Vertical pressure velocities were multiplied by 300 for plotting purposes, and a $10 \mathrm{~m} \mathrm{~s}^{-1}$ and $0.03 \mathrm{~Pa} \mathrm{~s}^{-1}$ reference vector is shown.

The composites shown here are based on a common linear regression technique (e.g., Wheeler and Kiladis 1999; Andersen and Kuang 2012), with the model OLR serving as a reference time series. The OLR is filtered by computing for each latitude the two-dimensional fast Fourier transform (FFT) in longitude and time, retaining only periods of 20-100 days and wavenumbers $1-3$, and then taking the inverse FFT. We identify the latitude of maximum filtered OLR variance, and the time series from all longitudinal points at that latitude are concatenated to extend the series. A similar concatenation is performed with the unfiltered fields of interest (e.g., $q$, $T$, or $u \partial h / \partial x$ ), and the fields are regressed (with zero lag) against the filtered OLR. This produces a spatial field of regression coefficients indicating the covariance of a given variable with intraseasonal OLR at the base point. A final composite is created by scaling the regression coefficients by twice the standard deviation of the filtered OLR series for each simulation.

Statistical significance is determined against a null hypothesis of no relationship between the OLR and the composite variable, and coefficients with $p$ values greater than 0.05 are rejected. In most cases, these constitute a small fraction of the total and are not indicated on the composite plots for the sake of clarity. In the $26^{\circ} \mathrm{C}$ case, intraseasonal variability was weak enough that a 10 -yr simulation only allowed a noisy composite; hence, we will use the $29^{\circ} \mathrm{C}$ case as the low SST end member in comparisons of composite fields.
We have also tested the robustness of the $35^{\circ} \mathrm{C}$ composite using an alternate methodology. Following Wheeler and Hendon (2004), we calculated a multivariate EOF-based index using OLR and 200-hPa and $850-\mathrm{hPa}$ zonal wind. The two leading EOFs together account for $44 \%$ of the intraseasonal variance between $10^{\circ} \mathrm{S}$ and $10^{\circ} \mathrm{N}$ and are well separated from the third mode (4\%). The first two modes have a zonal wavenumber one structure, with a $90^{\circ}$ relative phase shift, and their PCs are highly correlated $(r=0.87)$ at a 6 -day lag, indicating a single propagating mode with a 24-day return time, consistent with the peak in Fig. 3b. Composites created by linear regression against the first $\mathrm{PC}$ are virtually identical to the filtered OLR composites shown in this paper. Owing to the higher wavenumber of the MJO at low SST (roughly $k=2$ ), an EOF analysis does not neatly capture the MJO variability as two modes in quadrature. We therefore elected not to use this method in constructing our MSE budgets. However, the good agreement seen in the $35^{\circ} \mathrm{C}$ case reassures us that the filtered OLR composites are also dominated by a single MJO-like mode.

Vertical cross sections of the composite specific humidity, temperature, and wind vectors along the equator are shown in Fig. 5 for the $29^{\circ}$ and $35^{\circ} \mathrm{C}$ cases. Again, the greater magnitude from the high SST run is evident. We also note a significant westward tilt with height in each field. This tilt is seen in observations (e.g., Benedict and Randall 2007) and is generally attributed to shallow convection in advance of the precipitation maximum, leading to a moistening of the lower troposphere and 


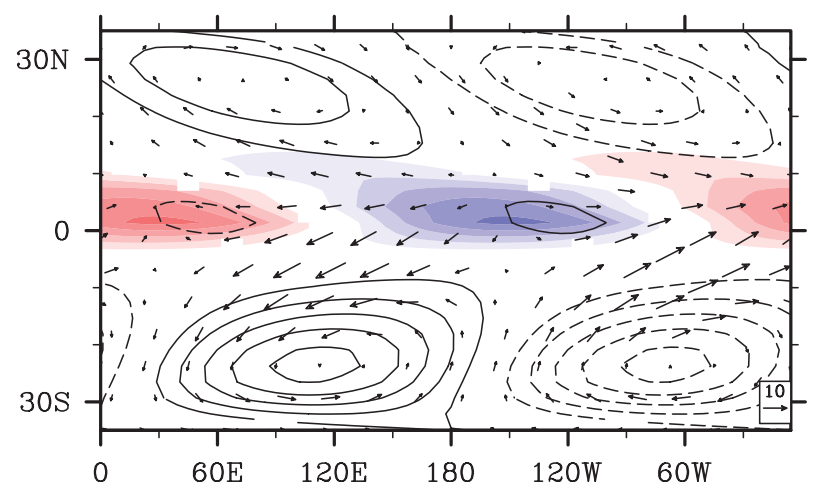

FIG. 6. Precipitation (shading) and 200-hPa geopotential height (solid contours) and wind anomalies in the $35^{\circ} \mathrm{C}$ case. Contour intervals are $2 \mathrm{~mm} \mathrm{day}^{-1}$ for precipitation and $12 \mathrm{~m}$ for geopotential height. A $10 \mathrm{~m} \mathrm{~s}^{-1}$ wind vector is shown for reference.

preconditioning the atmosphere for deep convection. The importance of the tilt is unclear, and its appearance with the MJO is irregular in models (Hannah and Maloney 2011). Hannah and Maloney found that the tilt decreases as a function of convective entrainment rate and rainfall reevaporation, and note that it does not appear in an aquaplanet version of the conventional CAM. The westward tilt appears less pronounced in SP-CAM simulations with continents and modern boundary conditions (Benedict and Randall 2009), although this may depend on the compositing method.

The composite 200-hPa geopotential height and circulation anomalies for the $35^{\circ} \mathrm{C}$ case show the familiar double gyre pattern associated with the MJO (Fig. 6). This pattern is typically interpreted as a Gill-like response (Gill 1980) to a pair of heating and cooling anomalies on the equator, associated with enhanced and suppressed convection, respectively (e.g., Seo and Son 2012). Precipitation (shading) is enhanced around $150^{\circ} \mathrm{W}$, a region of anomalous ascent and upper-level divergence, while anomalous descent, convergence, and suppressed precipitation are centered at $30^{\circ} \mathrm{E}$.

We repeat this compositing process for each term in the column-integrated MSE budget,

$$
\begin{aligned}
\left\langle\frac{\partial h}{\partial t}\right\rangle= & -\langle\mathbf{u} \cdot \nabla h\rangle-\left\langle\omega \partial_{p} h\right\rangle+\langle\mathrm{LW}\rangle \\
& +\langle\mathrm{SW}\rangle+\langle\mathrm{LH}\rangle+\langle\mathrm{SH}\rangle,
\end{aligned}
$$

consisting of horizontal (HA) and vertical (VA) advection, longwave (LW) and shortwave (SW) radiative heating, and surface latent $(\mathrm{LH})$ and sensible $(\mathrm{SH})$ heat fluxes and where

$$
\langle\Phi\rangle=\frac{1}{g} \int_{p s}^{p \text { top }} \Phi d p
$$

is a pressure integral from the surface to the model top.

The spatial structures of the composite budget terms for the $35^{\circ} \mathrm{C}$ case are shown in Fig. 7. The columnintegrated MSE anomaly has a zonal wavenumber-one structure with a westward phase tilt toward the poles, while the MSE tendency shows a similar pattern shifted $90^{\circ}$ to the east. The largest budget terms involve the advective and radiative tendencies, while latent and sensible surface fluxes are relatively small. Spatial structures in the $29^{\circ}$ and $32^{\circ} \mathrm{C}$ cases are qualitatively similar, though with a reduced magnitude and zonal extant. A detailed analysis of the $29^{\circ} \mathrm{C}$ case can be found in Andersen and Kuang (2012).

To estimate the importance of each term in maintaining the composite MSE anomaly, we calculate an area-weighted projection of each term onto the anomaly $\langle h\rangle$. The projection $F$ of a budget term $\Phi$ is given by the area integral of the product of $\langle\Phi\rangle$ and $\langle h\rangle$, taken over all longitudes and between $15^{\circ} \mathrm{S}$ and $15^{\circ} \mathrm{N}$, and normalized by $\langle h\rangle$ to give an effective forcing per unit MSE,

$$
F_{\Phi}=\frac{\iint\langle h\rangle\langle\Phi\rangle d A}{\iint\langle h\rangle\langle h\rangle d A} .
$$

Thus, the fractional change (i.e., the growth rate) of the average squared MSE anomaly $\langle h\rangle^{2}$ is equal to the sum of the projections of each term in the budget,

$$
\frac{\iint\langle h\rangle\left\langle\partial_{t} h\right\rangle d A}{\iint\langle h\rangle^{2} d A}=F_{\mathrm{HA}}+F_{\mathrm{VA}}+F_{\mathrm{LW}}+F_{\mathrm{SW}}+F_{\mathrm{LH}}+F_{\mathrm{SH}} .
$$

Our working assumption is that the increase in intraseasonal variability with SST is related to changes in one of the normalized terms: either a term providing a positive forcing becomes more efficient (more positive forcing per unit MSE) or a damping term becomes less efficient (less negative forcing per unit MSE). In either case, the projection of the responsible term should increase with SST. In principle, the normalized forcing of every term could remain constant even as MJO activity scales with SST, implying no change in the physical balance maintaining the MJO. Though possible, such a scenario seems unlikely given the strong nonlinearities present in certain terms but not others.

This procedure leads to composite MSE budgets that are qualitatively similar to that of Andersen and Kuang (2012). For all SSTs, the MSE anomaly is almost entirely maintained by longwave heating, which provides the strongest positive forcing (Fig. 8). These longwave 

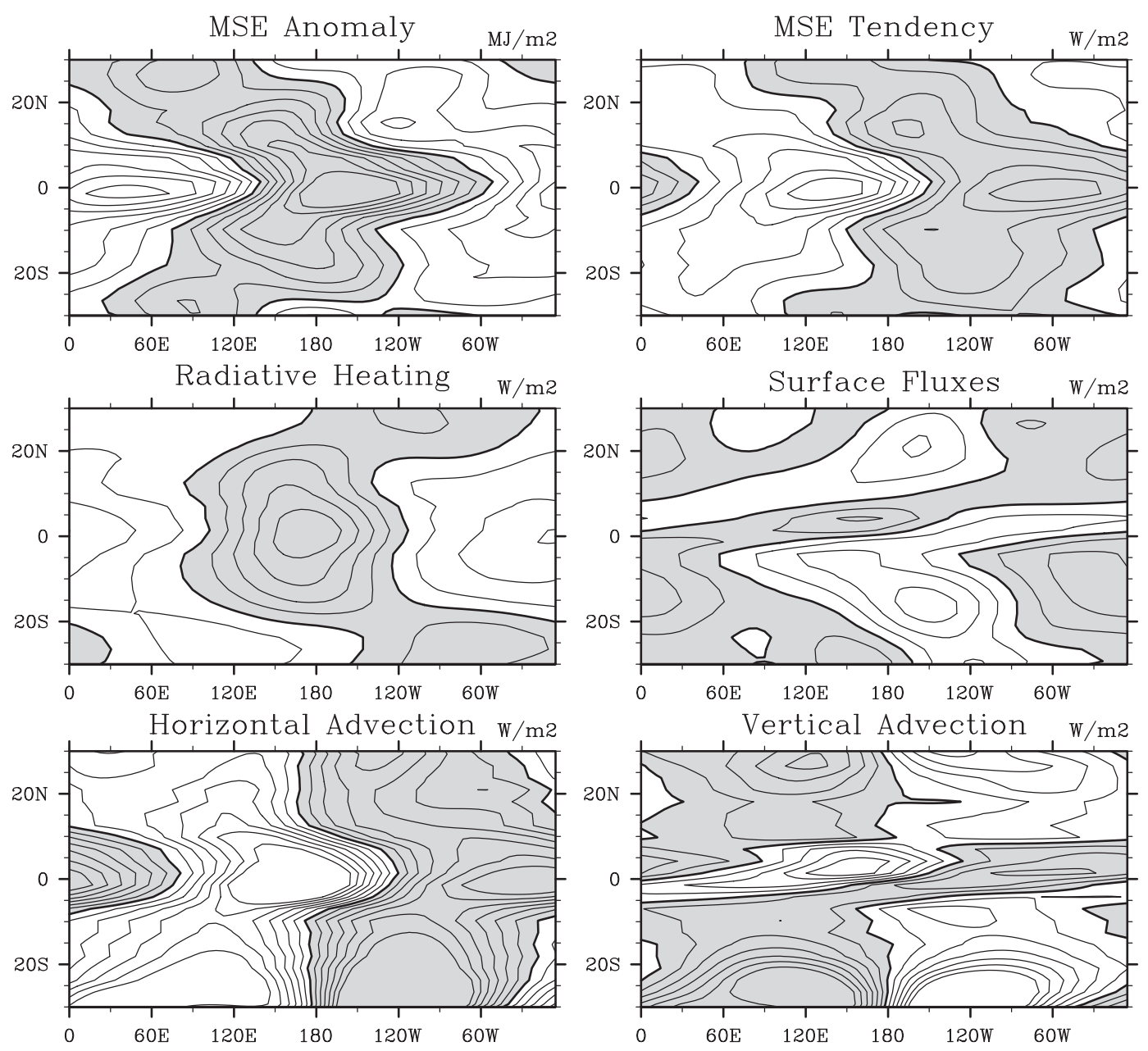

FIG. 7. Terms in the vertically integrated MSE budget for the $35^{\circ} \mathrm{C}$ case. Contour intervals for the MSE and MSE tendencies (including individual terms) are $2 \mathrm{MJ} \mathrm{m}^{-2}$ and $8 \mathrm{~W} \mathrm{~m}^{-2}$, respectively. The zero contour is in bold; positive values are shaded.

anomalies are largely due to the reduction in OLR by high clouds, with a smaller component associated with clear-sky water vapor (not shown).

The absolute, unnormalized longwave forcing increases with SST as one would expect, but the forcing per unit MSE, $F_{\mathrm{LW}}$, decreases. In particular, we find that the water vapor component of $F_{\mathrm{LW}}$ increases slightly, while the cloud-related component decreases by a greater amount. The level of maximum high cloud fraction remains at a constant temperature, consistent with the fixed anvil temperature (FAT) hypothesis of Hartmann and Larson (2002), which predicts that clouds will preferentially detrain near the level of maximum radiatively driven divergence. Since radiative cooling in the troposphere is largely determined by the vertical profile of water vapor, the high cloud fraction becomes closely tied to temperature through the Clausius-Clapeyron relationship. All else being equal, an increase in cloud height with SST implies a positive radiative feedback. However, because the additional water vapor at low levels reduces the upwelling longwave flux, the normalized cloud radiative forcing (i.e., the energetic impact) actually decreases. The combined water vapor and cloud effects lead to the observed decrease in longwave contribution to MSE maintenance $\left(F_{\mathrm{LW}}\right)$ with SST seen in Fig. 8.

This decrease indicates that, although longwave heating is consistently the largest positive term, it is likely not the cause of the strengthening MJO with increased SST. A more likely candidate is the vertical advection, which provides a negative feedback $\left(F_{\mathrm{VA}}<0\right)$ at low SST but becomes increasingly positive as the SST rises. To better understand the source of this change, we decompose the vertical term according to

$$
\omega=\bar{\omega}+\omega_{\mathrm{MJO}}+\omega_{r}
$$




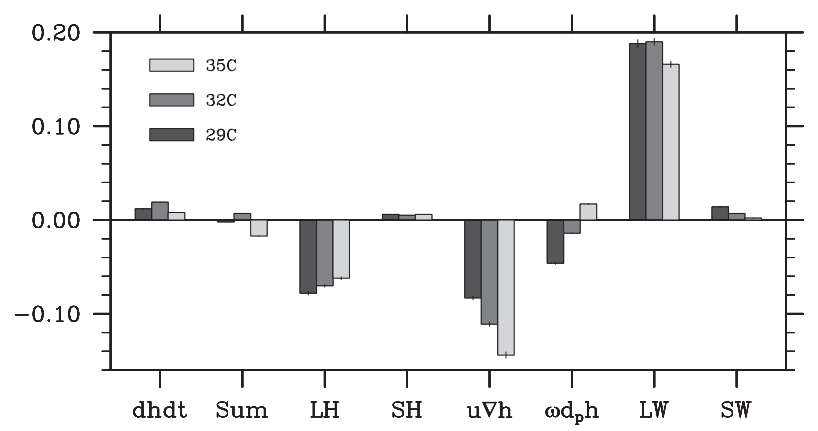

FIG. 8. Projections of each MSE budget term onto the MSE anomaly. A positive trend is seen in vertical advection. The sum of individual terms is shown next to the actual tendency for comparison. Error bars indicate the $95 \%$ confidence intervals associated with the regression coefficient at each point in space, propagated through the projection calculations.

and

$$
\frac{\partial h}{\partial p}=\frac{\overline{\partial h}}{\partial p}+\left(\frac{\partial h}{\partial p}\right)_{\mathrm{MJO}}+\left(\frac{\partial h}{\partial p}\right)_{r}
$$

in which overbars indicate a time average, the "MJO" subscript indicates a component correlated with the filtered OLR, and " $r$ " indicates the residual. With this decomposition, the product of $\omega$ and $\partial h / \partial p$ yields nine terms, six of which have projections on the composite MSE that are nearly or identically zero. The remaining three, $\omega_{\mathrm{MJO}} \overline{\partial h / \partial p}, \bar{\omega}(\partial h / \partial p)_{\mathrm{MJO}}$, and $\omega_{r}(\partial h / \partial p)_{r}$, are interpreted as the MJO advection of the mean MSE, the mean advection of the MJO perturbation MSE, and MJO modulation of vertical eddy transport. The projection of each component onto the MSE anomaly gives a sense of their relative contributions (Fig. 9) and indicates that the trend in vertical advection with SST is due to the MJO-related vertical velocity acting on the mean MSE gradient.

The mean vertical gradient, $\overline{\partial h / \partial p}$, is seen to become more positive below $400 \mathrm{hPa}$ throughout the model deep tropics (Fig. 10), and we suggest this may be the fundamental cause of the MJO amplification with SST. This shift is a thermodynamic consequence of maintaining a moist adiabat with little change in relative humidity while the SST is increased, and is effectively determined by the lower boundary condition. One consequence of the shift is to increase $-\omega_{\mathrm{MJO}} \overline{\partial h / \partial p}$ in regions of ascent $\left(\omega_{\mathrm{MJO}}<0\right)$, resulting in slower loss, or greater gain, of column MSE. If regions of anomalous ascent are correlated with regions of high column MSE $(\langle h\rangle>0)$ and descent with low MSE, then, all else being equal, the change in MSE profile will make the normalized forcing by the vertical advection term $F_{\mathrm{VA}}$ more positive [Eq. (2)]. This can be demonstrated by

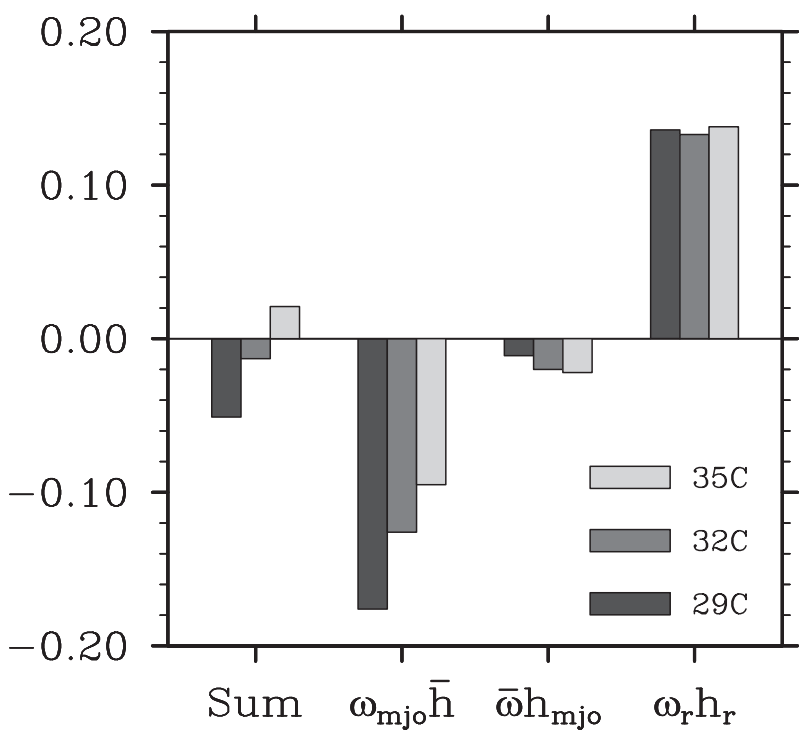

FIG. 9. Projections of each component of vertical advection onto the MSE anomaly, indicating that the positive trend with SST is associated with the MJO vertical velocity acting on the mean MSE gradient.

calculating $F_{\mathrm{VA}}$ using $\mathrm{MJO}$ vertical velocities and column MSE anomalies for the $29^{\circ} \mathrm{C}$ case but substituting the mean MSE gradient $\overline{\partial h / \partial p}$ from the $35^{\circ} \mathrm{C}$ case. This results in a change in $F_{\mathrm{VA}}$ from -0.18 to -0.06 . However, when all fields are taken from the $35^{\circ} \mathrm{C}$ case, $F_{\mathrm{VA}}$ is reduced to -0.09 (Fig. 9). Thus, the change in $\overline{\partial h / \partial p}$ alone can account for a greater effect than is actually seen in the model. This indicates that shifts in vertical velocity may be partially compensating for the change in $\overline{\partial h / \partial p}$.

In fact, some compensation is expected. The vertical advection term considered here is closely related to the gross moist stability $M$ (Neelin and Held 1987), often defined (e.g., Yu et al. 1998) as

$$
M=-\int \omega \frac{\partial h}{\partial p} d p .
$$

It has been pointed out (e.g., Chou and Neelin 2004) that changes in $M$ with SST involve the near cancellation of two effects. First, a warmer surface allows greater low-level moisture, which tends to reduce $M$ through its effect on $\partial h / \partial p$. Second, this moisture also tends to increase the depth of convection, altering the profile of $\omega$ and causing $M$ to increase. The observed gross moist stability is nearly constant throughout the tropics as a result of this balance (Yu et al. 1998). In our simulations, the first effect appears to exceed the second, allowing a decrease in $M$ and an increase in $F_{\mathrm{VA}}$. 


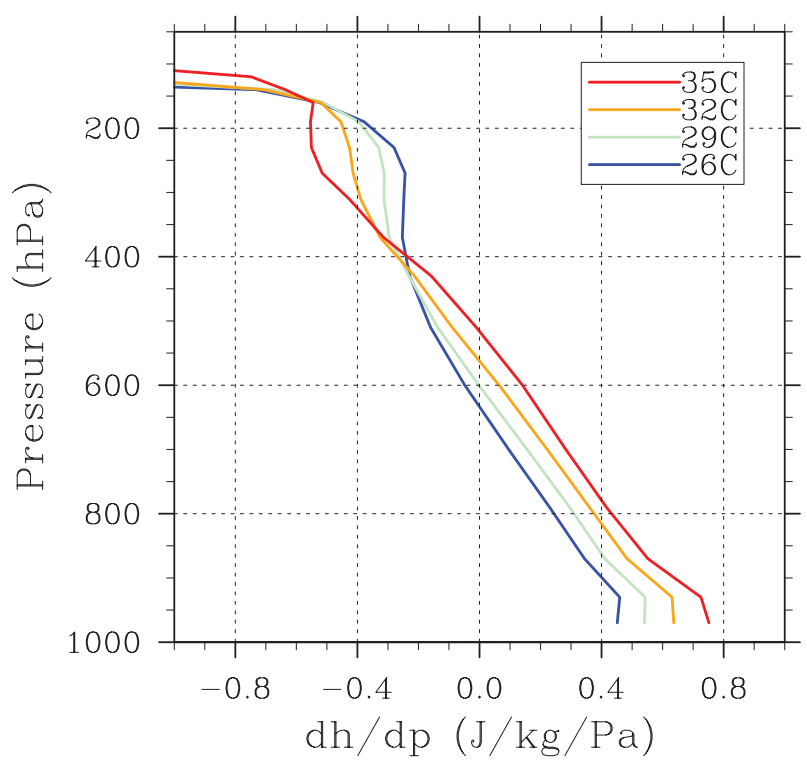

FIG. 10. The mean vertical gradient of MSE, $\overline{\partial h / \partial p}$, averaged zonally and between $0^{\circ}$ and $10^{\circ} \mathrm{N}$, is increasingly positive below $400 \mathrm{hPa}$ as SST is increased.

\section{Discussion}

In addition to the generic issues of an aquaplanet configuration, there are other differences in physics and boundary conditions that may affect the relevance of our results to MJO behavior in warm climates. Our simulations use fixed ocean surface temperatures with the same meridional gradient specified independent of the mean temperature. Interactive SST has been shown to improve MJO simulation and enhance intraseasonal variance, although it does not appear to be critical to the generation of an MJO (e.g., Maloney and Sobel 2004; Kemball-Cook et al. 2002). We note that, although the SST is held fixed in our runs, surface fluxes may still vary as a function of the atmospheric state and do contribute to the MJO energy budget. Benedict and Randall (2009) suggest that use of interactive SST may reduce intraseasonal variance in SP-CAM.

The meridional SST gradient may also affect MJO behavior, and a multitude of modeling and observational evidence suggests that the gradient tends to weaken in warmer climates. The dependence of organized convection on the meridional gradient was not systematically studied here, and results from existing studies are ambiguous. Grabowski (2004) found robust MJO-like variability in a model with globally uniform SST, suggesting that gradients are at least not fundamental to the MJO, while Maloney et al. (2010) found that intraseasonal variability increased in an aquaplanet version of CAM3 when the prescribed meridional SST gradient was reduced.
Despite the idealizations listed above, the MJO simulated here maintains a structure in humidity, temperature, and wind that qualitatively resembles observations and varies principally only in magnitude across the simulations presented here. As in many previous studies, it appears to be consistent with the recharge-discharge paradigm (Blade and Hartmann 1993) in which the MJO time scale is determined by the buildup and discharge of environmental humidity, as well as the idea that the MJO is a "moisture mode" (Raymond and Fuchs 2009), which requires an effectively negative gross moist stability for its existence.

The present work differs from some previous composite MSE budgets. While many models suggest a dominant or essential role for latent heat fluxes (Maloney et al. 2010; Sobel et al. 2008), the MJO simulated here and in Andersen and Kuang (2012) is principally supported by longwave heating. This term is usually secondary in other models, serving as a positive feedback rather than a prerequisite for instability. Grabowski (2004), for example, found that interactive radiation was unnecessary to produce an MJO. It is not entirely surprising that both radiative heating and surface fluxes can play a dominant role in intraseasonal variability, depending on the model. Both processes have similar energetic effects, resulting in a net transfer of heat from ocean to atmosphere, and are somewhat interchangeable as far as the column MSE is concerned (Sobel et al. 2010). These terms were combined by Kiranmayi and Maloney (2011) in their composite MSE budget of observed MJO events, and it is unclear whether a single process is dominant in the real world.

Determining the mechanism behind the MJO increase with SST based on trends in composite MSE budget terms [Eq. (1)] relies on a number of assumptions. The composite budgets presented here represent not only an estimate of some average MJO event but an average over the full life cycle of that event; they do not account for differences between growth, decay, or steady-state phases. For example, longwave heating per unit MSE could be greater than average during the period of initial MSE anomaly growth and less than average during decay. Note that growth/decay here refers to the amplitude of the global pattern of MSE anomaly, rather than the trend at a single point in space, which would vary throughout an MJO event due to pattern propagation, even if the pattern amplitude remained constant. We have explored limiting the composite to periods of pattern growth or decay and found qualitatively similar results: for example, the trend in vertical advection appears to be robust. However, owing to the shorter effective time series, these growth/decay period composites tend to be noisy and are not shown. 
A single budget term may also reflect several distinct physical processes: for example, longwave heating is associated with both cloud and water vapor anomalies, horizontal advection can be related to the mean flow and transient eddies, etc. Suppose that two physical processes, $\mathrm{A}$ and $\mathrm{B}$, are contained within the same budget term $\Phi$, so the projection is given by $F_{\Phi}=F_{\mathrm{A}}+F_{\mathrm{B}}$. An increase in SST may produce a positive change in $F_{\mathrm{A}}$, which leads to a larger MSE anomaly. Since the anomaly does not grow indefinitely, the positive change in $F_{\mathrm{A}}$ is ultimately balanced by negative changes elsewhere (i.e., nonlinear damping). If these negative changes were confined to $F_{\mathrm{B}}$, then $F_{\Phi}$ would show no net change, and we may conclude that a different term was responsible for the larger MSE anomaly. One defense against this possibility is to decompose each budget term into component physical processes where possible. It also seems unlikely that the additional damping would be contained entirely in the same term as the additional forcing; in Fig. 8, every significant term but one (longwave heating) is acting to dissipate the MSE anomaly, and every term but two (latent heat fluxes and vertical advection) show a negative trend with SST.

\section{Conclusions}

We have found that tropical intraseasonal variability in a superparameterized version of the NCAR Community Atmosphere Model is strongly dependent on the prescribed value of mean sea surface temperature. In aquaplanet simulations with equatorial SST near $26^{\circ}$, $29^{\circ}, 32^{\circ}$, and $35^{\circ} \mathrm{C}$, the intraseasonal (wavenumbers $1-3$, periods $20-100$ days) variance increases dramatically and monotonically with SST. The intraseasonal variance of outgoing longwave radiation, for example, triples between the $26^{\circ}$ and $35^{\circ} \mathrm{C}$ cases, and the ratio of eastward progating to westward propagating variance increases from 1.95 to 6.27 . The intraseasonal variance in all simulations is dominated by a global-scale, eastwardpropagating convective disturbance that resembles the observed Madden-Julian oscillation (MJO).

A similar increase in MJO-like variability was found previously in the conventional version of CAM (Caballero and Huber 2010), although no mechanism was proposed, and the model's lack of MJO simulation skill under modern conditions makes interpretation problematic. These models are similar, but those aspects in which they differ most-their representations of convection and radiative transfer-lie at the heart of MJO physics, suggesting that this behavior may be fairly robust.

We explored the reasons for the intraseasonal variance increase in SP-CAM by calculating a column-integrated moist static energy (MSE) budget for a composite MJO event. The contribution of each term to the steady-state maintenance of the MJO-related MSE anomaly was estimated from the spatial projection of each budget term onto the anomaly. Consistent with previous work by Andersen and Kuang (2012), this analysis indicated that the MSE anomaly is primarily supported by the radiative effects of high clouds, while anomalous horizontal advection drives eastward propagation. However, as SST is increased, both of these terms show increasingly negative projections on the anomaly and, thus, cannot be responsible for the observed amplification. In contrast, the projection of vertical advection shows a positive trend: at low SST it provides a strong damping but it becomes an energy source at high SST. This leads us to conclude that changes in vertical MSE advection are likely responsible for the increase in MJO variability with SST.

A decomposition of the vertical advection term indicates that its positive trend with SST is associated with the intraseasonal vertical velocity acting on the mean MSE gradient. We suggest that an increase in the mean MSE vertical gradient in the model's tropical lower troposphere may be a contributing factor. This would serve to increase the MSE buildup associated with a given vertical mass flux and effectively reduce the gross moist stability. This change in the MSE profile is a direct consequence of increasing SST while maintaining a moist adiabat and fixed relative humidity, and should be a robust feature of warm climates.

This behavior warrants further investigation with independent models, in particular those whose simulation of the MJO differs from CAM. Lee (1999) noted an increase in intraseasonal variance in a GFDL AGCM after a uniform $2^{\circ} \mathrm{C}$ SST increase, and Huang and Weickmann (2001) reported a trend in equatorial zonal winds in a transient global warming simulation with the Canadian Climate Centre Model, which the authors speculate was driven by changes in equatorial variability. Besides these two early examples, we are unaware of any other models that exhibit a strong dependence of intraseasonal variance on SST.

This work has implications for past warm climates, as well as future scenarios in which greenhouse gas emissions remain unchecked. Previous work has linked the MJO to a number of climate phenomena, including the Asian and Australian monsoons (e.g., Wheeler and Hendon 2004), ENSO (e.g., McPhaden 1999), tropical cyclogenesis (e.g., Frank and Roundy 2006), and dynamic warming of the Arctic (Lee et al. 2011). Changes in any one of these could have significant impacts on human society. We also note that the MJO has a nonnegligible impact on the equatorial momentum budget (Lee 1999); this is due to the tilted upper-tropospheric gyre 
circulations associated with organized convection, which produce equatorward fluxes of westerly momentum.

Increases in MJO activity could lead to reduced equatorial easterlies, which might be sufficient to explain the Pliocene "permanent El Niño" seen in proxy SST data, through their impact on upwelling (Tziperman and Farrell 2009). Sufficiently large increases in MJO activity could lead to outright westerly winds or superrotation (Pierrehumbert 2000; Held 1999), although, if the sensitivity to SST seen in SP-CAM is an accurate reflection of the real world, strong superrotation would require surface temperatures last seen during the Eocene (Pearson et al. 2007).

Acknowledgments. The authors thank three reviewers for their insightful and helpful comments. This work was supported by NSF Climate Dynamics Grants ATM0902844 P2C2 (NA, ET), ATM-0754332 (NA, ZK, ET), and AGS-1062016 (ZK). ET thanks the Weizmann Institute for its hospitality during parts of this work. The model computations were run on the Odyssey cluster supported by the FAS Science Division Research Computing Group at Harvard University.

\section{REFERENCES}

Andersen, J. A., and Z. Kuang, 2012: Moist static energy budget of MJO-like disturbances in the atmosphere of a zonally symmetric aquaplanet. J. Climate, 25, 2782-2804.

Arnold, N. P., E. Tziperman, and B. Farrell, 2012: Abrupt transition to strong superrotation driven by equatorial wave resonance in an idealized GCM. J. Atmos. Sci., 69, 626-640.

Benedict, J. J., and D. A. Randall, 2007: Observed characteristics of the MJO relative to maximum rainfall. J. Atmos. Sci., 64, 2332-2354.

—_, and - 2009: Structure of the Madden-Julian oscillation in the superparameterized CAM. J. Atmos. Sci., 66, 32773296.

Blade, I., and D. L. Hartmann, 1993: Tropical intraseasonal oscillations in a simple nonlinear model. J. Atmos. Sci., 50, 29222939.

Bony, S., J.-L. Dufresne, H. L. Le Treut, J.-J. Morcrette, and C. Senior, 2004: Dynamic and thermodynamic components of cloud changes. Climate Dyn., 22, 71-86.

Caballero, R., and M. Huber, 2010: Spontaneous transition to superrotation in warm climates simulated by CAM3. Geophys. Res. Lett., 37, L11701, doi:10.1029/2010GL043468.

Chou, C., and J. D. Neelin, 2004: Mechanisms of global warming impacts on regional tropical precipitation. J. Climate, 17, 2688-2701.

Dowsett, H. J., and M. M. Robinson, 2009: Mid-Pliocene equatorial Pacific sea surface temperature reconstruction: A multi-proxy perspective. Philos. Trans. Roy. Soc. London, 367, 109-125.

Frank, W. M., and P. E. Roundy, 2006: The role of tropical waves in tropical cyclogenesis. Mon. Wea. Rev., 134, 2397-2417.

Fuchs, Z., and D. J. Raymond, 2002: Large-scale modes of a nonrotating atmosphere with water vapor and cloud-radiation feedbacks. J. Atmos. Sci., 59, 1669-1679.
Gill, A. E., 1980: Some simple solutions for heat-induced tropical circulation. Quart. J. Roy. Meteor. Soc., 106, 447-462.

Grabowski, W. W., 2001: Coupling cloud processes with the largescale dynamics using the Cloud-Resolving Convection $\mathrm{Pa}$ rameterization (CRCP). J. Atmos. Sci., 58, 978-997.

_ 2003: MJO-like coherent structures: Sensitivity simulations using the Cloud-Resolving Convection Parameterization (CRCP). J. Atmos. Sci., 60, 847-864.

_ 2004: An improved framework for superparameterization. J. Atmos. Sci., 61, 1940-1952.

Grodsky, S. A., A. Bentamy, J. A. Carton, and R. T. Pinker, 2009: Intraseasonal latent heat flux based on satellite observations. J. Climate, 22, 4539-4556.

Hannah, W. M., and E. D. Maloney, 2011: The role of moisture convection feedbacks in simulating the Madden-Julian oscillation. J. Climate, 24, 2754-2770.

Hartmann, D. L., and K. Larson, 2002: An important constraint on tropical cloud-climate feedback. Geophys. Res. Lett., 29, 1951, doi:10.1029/2002GL015835.

Hayashi, Y.-Y., and A. Sumi, 1986: The 30-40 day oscillations simulated in an aqua planet model. J. Meteor. Soc. Japan, 64, 451-467.

Held, I. M., 1999: Equatorial superrotation in Earth-like atmospheric models. Proc. Bernhard Haurwitz Memorial Lecture, Dallas, TX, Amer. Meteor. Soc., 1-24. [Available online at http://www.gfdl.noaa.gov/cms-filesystem-action/user_files/ ih/lectures/super.pdf.]

— , and B. J. Soden, 2006: Robust responses of the hydrological cycle to global warming. J. Climate, 19, 5686-5699.

Hendon, H. H., C. Zhang, and J. D. Glick, 1999: Interannual variation of the Madden-Julian oscillation during austral summer. J. Climate, 12, 2538-2550.

Huang, H.-P., and K. M. Weickmann, 2001: Trend in atmospheric angular momentum in a transient climate change simulation with greenhouse gas and aerosol forcing. J. Climate, 14, 1525-1534.

Jones, C., and L. M. Carvalho, 2006: Changes in the activity of the Madden-Julian oscillation during 1958-2004. J. Climate, 19, 6353-6370.

Kemball-Cook, S., B. Wang, and X. Fu, 2002: Simulation of the intraseasonal oscillation in the ECHAM-4 model: The impact of coupling with an ocean model. J. Atmos. Sci., 59, 1433-1453.

Khairoutdinov, M. F., and D. A. Randall, 2001: A cloud resolving model as a cloud parameterization in the NCAR Community Climate System Model: Preliminary results. Geophys. Res. Lett., 28, 3617-3620.

— , and —, 2003: Cloud resolving modeling of the ARM summer 1997 IOP: Model formulation, results, uncertainties, and sensitivities. J. Atmos. Sci., 60, 607-625.

,-- , and C. DeMott, 2005: Simulations of the atmospheric general circulation using a cloud-resolving model as a superparameterization of physical processes. J. Atmos. Sci., 62 , 2136-2154.

Kiladis, G. N., K. H. Straub, and P. T. Haertel, 2005: Zonal and vertical structure of the Madden-Julian oscillation. J. Atmos. Sci., 62, 2790-2809.

—, M. C. Wheeler, P. T. Haertel, K. H. Straub, and P. E. Roundy, 2009: Convectively coupled equatorial waves. Rev. Geophys., 47, RG2003, doi:10.1029/2008RG000266.

Kim, D., and Coauthors, 2009: Application of MJO simulation diagnostics to climate models. J. Climate, 22, 6413-6436.

_ A. H. Sobel, and I.-S. Kang, 2011: A mechanism denial study on the Madden-Julian oscillation. J. Adv. Model. Earth Syst., 3, M12007, doi:10.1029/2011MS000081. 
Kiranmayi, L., and E. D. Maloney, 2011: The intraseasonal moist static energy budget in reanalysis data. J. Geophys. Res., 116, D21117, doi:10.1029/2011JD016031.

Kraucunas, I., and D. L. Hartmann, 2005: Equatorial superrotation and the factors controlling the zonal-mean zonal winds in the tropical upper troposphere. J. Atmos. Sci., 62, 371-389.

Kuang, Z., 2008: A moisture-stratiform instability for convectively coupled waves. J. Atmos. Sci., 65, 834-854.

_ 2011: The wavelength dependence of the gross moist stability and the scale selection in the instability of column-integrated moist static energy. J. Atmos. Sci., 68, 61-74.

Lee, M.-I., I.-S. Kang, and B. E. Mapes, 2003: Impacts of cumulus convection parameterization on aqua-planet AGCM simulations of tropical intraseasonal variability. J. Meteor. Soc. Japan, 81, 963-992.

Lee, S., 1999: Why are the climatological zonal winds easterly in the equatorial upper troposphere? J. Atmos. Sci., 56, 1353-1363.

_ - S. Feldstein, D. Pollard, and T. White, 2011: Do planetary wave dynamics contribute to equable climate? J. Climate, $\mathbf{2 4}$, 2391-2404.

Lin, J.-L., M. Zhang, and B. Mapes, 2005: Zonal momentum budget of the Madden-Julian oscillation: The source and strength of equivalent linear damping. J. Atmos. Sci., 62, 2172-2188.

- , G. N. Kiladis, B. E. Mapes, K. M. Weickmann, K. R. Sperber, W. Lin, M. C. Wheeler, and S. D. Schubert, 2006: Tropical intraseasonal variability in 14 IPCC AR4 climate models. Part I: Convective signals. J. Climate, 19, 2665-2690.

Madden, R. A., and P. R. Julian, 1971: Detection of a 40-50 day oscillation in the zonal wind in the tropical Pacific. J. Atmos. Sci., 28, 702-708.

Majda, A. J., and J. A. Biello, 2004: A multiscale model for tropical intraseasonal oscillations. Proc. Natl. Acad. Sci. USA, 101, 4736-4741.

_ , and S. N. Stechmann, 2009: The skeleton of tropical intraseasonal oscillations. Proc. Natl. Acad. Sci. USA, 106, $8417-$ 8422.

Maloney, E. D., 2009: The moist static energy budget of a composite tropical intraseasonal oscillation in a climate model. J. Climate, 22, 711-729.

_- and A. H. Sobel, 2004: Surface fluxes and ocean coupling the tropical intraseasonal oscillation. J. Climate, 17, 4368-4386.

,-- , and W. M. Hannah, 2010: Intraseasonal variability in an aquaplanet general circulation model. J. Adv. Model. Earth Syst., 2, 1-24.

Mapes, B., 2000: Convective inhibition, subgridscale triggering, and stratiform instability in a toy tropical wave model J. Atmos. Sci., 57, 1515-1535.

Matsuno, T., 1966: Quasi-geostrophic motions in the equatorial area. J. Meteor. Soc. Japan, 44, 25-42.

McPhaden, M. J., 1999: Genesis and evolution of the 1997-98 El Niño. Science, 382, 950-954.

Meehl, G. A., and Coauthors, 2007: Global climate projections. Climate Change 2007: The Physical Science Basis, S. Solomon et al., Eds., Cambridge University Press, 747-845.

Muller, C., P. A. O'Gorman, and L. E. Back, 2011: Intensification of precipitation extremes with warming in a cloud-resolving model. J. Climate, 24, 2784-2800.

Neelin, J. D., and I. M. Held, 1987: Modeling tropical convergence based on the moist static energy budget. Mon. Wea. Rev., 115, 3-12.

Numaguti, A., and Y.-Y. Hayashi, 1991: Behavior of cumulus activity and the structures of circulations in an aqua planet model, part II: Eastward-moving planetary scale structure and the intertropical convergence zone. J. Meteor. Soc. Japan, 69, $563-579$

Oliver, E. C., and K. R. Thompson, 2012: A reconstruction of Madden-Julian oscillation variability from 1905 to 2008. J. Climate, 25, 1996-2019.

Pearson, P. N., B. E. van Dongen, C. J. Nicholas, and R. D. Pancost, 2007: Stable warm tropical climate through the Eocene epoch. Geology, 35, 211-214.

Pierrehumbert, R., 2000: Climate change and the tropical Pacific: The sleeping dragon wakes. Proc. Natl. Acad. Sci. USA, 97, 1355-1358.

Randall, D., M. Khairoutdinov, A. Arakawa, and W. Grabowski, 2003: Breaking the cloud parameterization deadlock. Bull. Amer. Meteor. Soc., 84, 1547-1564.

Raymond, D. J., 2001: A new model of the Madden-Julian oscillation. J. Atmos. Sci., 58, 2807-2819.

and Z. Fuchs, 2009: Moisture modes and the Madden-Julian oscillation. J. Climate, 22, 3031-3046.

- S. L. Sessions, A. H. Sobel, and Z. Fuchs, 2009: The mechanics of gross moist stability. J. Adv. Model. Earth Syst., 1, 9, doi:10.3894/JAMES.2009.1.9.

Roundy, P. E., 2012: Observed structure of convectively coupled waves as a function of equivalent depth: Kelvin waves and the Madden-Julian oscillation. J. Atmos. Sci., 69, 2097-2106. , and W. M. Frank, 2004: A climatology of waves in the equatorial region. J. Atmos. Sci., 61, 2105-2132.

Seo, K.-H., and S.-W. Son, 2012: The global atmospheric circulation response to tropical diabatic heating associated with the Madden-Julian oscillation during northern winter. J. Atmos. Sci., 69, 79-96.

Sobel, A., and E. Maloney, 2012: An idealized semi-empirical framework for modeling the Madden-Julian oscillation. J. Atmos. Sci., 69, 1691-1705.

_ - J. Nilsson, and L. Polvani, 2001: The weak temperature gradient approximation and balanced tropical moisture waves. J. Atmos. Sci., 58, 3650-3665.

- E. D. Maloney, G. Bellon, and D. M. Frierson, 2008: The role of surface heat fluxes in tropical intraseasonal oscillations. Nat. Geosci., 1, 653-657.

,,--- , and,- 2010 : Surface fluxes and tropical intraseasonal variability a reassessment. J. Adv. Model. Earth Syst., 2, 2, doi:10.3894/JAMES.2010.2.2.

Swinbank, R., T. Palmer, and M. Davey, 1988: Numerical simulations of the Madden and Julian oscillation. J. Atmos. Sci., 45, 774-788.

Thayer-Calder, K., and D. A. Randall, 2009: The role of convective moistening in the Madden-Julian oscillation. J. Atmos. Sci., 66, 3297-3312.

Tziperman, E., and B. Farrell, 2009: Pliocene equatorial temperature: Lessons from atmospheric superrotation. Paleoceanography, 24, PA1101, doi:10.1029/2008PA001652.

Wheeler, M., and G. N. Kiladis, 1999: Convectively coupled equatorial waves: Analysis of clouds and temperature in the wavenumber-frequency domain. J. Atmos. Sci., 56, 374-399.

— , and H. H. Hendon, 2004: An all-season real-time multivariate MJO index: Development of an index for monitoring and prediction. Mon. Wea. Rev., 132, 1917-1932.

$\mathrm{Wu}$, C.-H., and H.-H. Hsu, 2009: Topographic influence on the MJO in the Maritime Continent. J. Climate, 22, 5433-5448.

Yu, J.-Y., C. Chou, and J. D. Neelin, 1998: Estimating the gross moist stability of the tropical atmosphere. J. Atmos. Sci., 55, 1354-1372.

Zhang, C., 2005: Madden-Julian oscillation. Rev. Geophys., 43, RG2003, doi:10.1029/2004RG000158. 